\title{
Mild Cognitive Impairment: A Systematic Review
}

\author{
Elena Mariani $^{\mathrm{a}, 1}$, Roberto Monastero ${ }^{\mathrm{b}, 1}$ and Patrizia Mecocci ${ }^{\mathrm{a}, *}$ \\ ${ }^{a}$ Section of Gerontology and Geriatrics, Department of Clinical and Experimental Medicine, University of Perugia, \\ Perugia, Italy \\ ${ }^{\mathrm{b}}$ Laboratory of Epidemiology and Psychology of Aging and Dementia, Department of Clinical Neuroscience, \\ University of Palermo, Palermo, Italy
}

\begin{abstract}
MCI is a nosological entity proposed as an intermediate state between normal aging and dementia. The syndrome can be divided into two broad subtypes: amnestic MCI (aMCI) characterized by reduced memory, and non-amnestic MCI (naMCI) in which other cognitive functions rather than memory are mostly impaired. aMCI seems to represent an early stage of AD, while the outcomes of the naMCI subtypes appear more heterogeneous -including vascular dementia, frontotemporal dementia or dementia with Lewy bodies- but this aspect is still under debate. MCI in fact represents a condition with multiple sources of heterogeneity, including clinical presentation, etiology, and prognosis. To improve classification and prognosis, there is a need for more sensitive instruments specifically developed for MCI as well as for more reliable methods to determine its progression or improvement. Current clinical criteria for MCI should be updated to include restriction in complex ADL; also the diagnostic and prognostic role of behavioral symptoms and motor dysfunctions should be better defined. A multidisciplinary diagnostic approach including biological and neuroimaging techniques may probably represent the best option to predict the conversion from MCI to dementia. In this review we discuss the most recent aspects related to the epidemiological, clinical, neuropathological, neuroimaging, biochemical and therapeutic aspects of MCI, with specific attention to possible markers of conversion to dementia.
\end{abstract}

Keywords: Alzheimer disease, apolipoprotein E, biomarkers, diagnosis, mild congnitive impairment

\section{INTRODUCTION}

Over the last decade a great amount of scientific effort has focused on the gray area between cognitively normal aging and dementia in order to define what can still be considered normal at different ages and what, on the other hand, is already the prodromal phase of an clinically disclosed dementia. The concept of "cognitive impairment not yet dementia" has been depicted by different definitions with variable prognosis (Table 1). Among them, Mild Cognitive Impairment (MCI) has become the term most frequently used and defined by

\footnotetext{
${ }^{1}$ Equal contribution.

*Corresponding author: Patrizia Mecocci, MD, PhD, Institute of Gerontology and Geriatrics, University of Perugia, Policlinico Monteluce-Padiglione E, Via Brunamonti 51, 06122 Perugia, Italy. Tel.: +39 075578 3270; Fax: +39 075573 0259; E-mail: mecocci@unipg.it.
}

slight impairment in cognitive functions with otherwise normal function in the activities of daily living [103].

The original criteria of MCI were related to an amnestic form, lately defined as aMCI, characterized by the presence of isolated memory impairment, memory complaint, relatively intact activities of daily living, normal general cognitive function and absence of dementia [99]. Using this definition in population studies, it was shown that aMCI constituted only a relatively small group, compared with all individuals with a much broader form of mild cognitive deficits in other cognitive functions such as language, attention, visuospatial skills, and executive functioning [46,65,70, 111]. Thus, Petersen [103] revised the original criteria and four different MCI subtypes have been proposed: (1) the former aMCI; (2) single non memory MCI (snmMCI), with isolated impairment of a cognitive domain other than memory; (3) multiple domain amnes- 
Table 1

Clinical terms proposed to define cognitive impairment not yet dementia

\begin{tabular}{|c|c|c|}
\hline Term & Initial description & Diagnostic criteria \\
\hline $\begin{array}{l}\text { Age-associated memory } \\
\text { impairment }\end{array}$ & Crook and co-workers [28] & $\begin{array}{l}\text { Subjective memory impairment with objective memory impairment } \\
\text { compared with that of a young adult }\end{array}$ \\
\hline Late-life forgetfulness & Blackford, LaRue [19] & $\begin{array}{l}\text { Age-associated memory impairment plus age-adjusted deficits in four } \\
\text { or more specific cognitive tests }\end{array}$ \\
\hline Mild cognitive decline & ICD-10 [128] & $\begin{array}{l}\text { Impairments in cognitive tests of learning, memory, or concentration } \\
\text { secondary to defined illness }\end{array}$ \\
\hline Questionable dementia & Morris [91] & Scoring 0.5 at Clinical Dementia Rating scale \\
\hline $\begin{array}{l}\text { Aging-associated cognitive } \\
\text { decline }\end{array}$ & Levy [67] & Age-adjusted impairment on any cognitive task \\
\hline Mild neurocognitive decline & DSM IV [2] & $\begin{array}{l}\text { Impairments in memory, learning, perceptual-motor, linguistic, or exec- } \\
\text { utive functioning }\end{array}$ \\
\hline $\begin{array}{l}\text { Cognitive impairment-no } \\
\text { dementia }\end{array}$ & Graham and co-workers [51] & $\begin{array}{l}\text { Impairments in memory, learning, perceptual-motor, linguistic or exec- } \\
\text { utive functioning in the absence of clinically defined dementia }\end{array}$ \\
\hline Mild Cognitive dysfunction & Johansson and Zarit [59] & Dysfunction according to five cognitive tests \\
\hline MCI & Petersen and co-workers [99] & $\begin{array}{l}\text { Subjective complaint of memory impairment with objective memory } \\
\text { impairment adjusted for age and education in the absence of dementia. } \\
\text { The definition was then expanded to include four clinical MCI subtype }\end{array}$ \\
\hline $\begin{array}{l}\text { Subclinical cognitive } \\
\text { impairment }\end{array}$ & Ritchie and co-workers [112] & $\begin{array}{l}\text { Scoring below a specific scor on the Dètèrioration Cognitive Observèe, } \\
\text { a test sensitive to early change in cognitive functioning }\end{array}$ \\
\hline $\begin{array}{l}\text { Cognitive impairment, no } \\
\text { dementia }\end{array}$ & De Ronchi and co-workers [34] & $\begin{array}{l}\text { Scoring } 2 \text { or more S.D. below the mean score of MMSE, corrected for } \\
\text { age and education, calculated among the non-demented people }\end{array}$ \\
\hline
\end{tabular}

Modified from De Carli [32].

tic $\mathrm{MCI}\left(\mathrm{mdMCI}^{+}\right)$, characterized by a slight impairment of multiple cognitive domains including memory; (4) multiple domains non amnestic $\mathrm{MCI}\left(\mathrm{mdMCI}^{-}\right)$, with a slight impairment of multiple cognitive domains but without memory deficits. However, there is still a lack of consensus on what types of cognitive tests, how many, and what thresholds or cut-off should be used to support or corroborate the diagnosis of MCI [72].

Longitudinal studies suggested that MCI represents a condition at high risk of progression to dementia, but rates of conversion vary among studies. Progression to dementia generally appears to be higher in clinicbased studies with a yearly incidence of about 10-15\%. Instead, population-based studies report lower rates, ranging from 5 to $10 \%$ per year $[32,95]$. Moreover, in population-based studies, a significant rate of reversion (20-25\%) from mild cognitive impairment to normal cognition and functioning was observed [94,111]. The discrepancy of progression rates to dementia between clinic- vs population-based studies probably reflects differences in population characteristics, length of follow-up and definition of cognitive impairment. Furthermore, the possibility of selection bias should be taken into account when examining data from clinicbased study.

According to the proposed four clinical subtypes of MCI, it is conceivable that they differ in etiology and outcome. In fact, aMCI and $\mathrm{mdMCI}^{+}$are considered to have a high likelihood of progression to Alzheimer's disease (AD), while snmMCI and $\mathrm{mdMCI}^{-}$are as- sumed to convert more frequently to non-AD dementia $[12,98,103]$. This aspect was recently confirmed by a German longitudinal study showing that, at sixyear follow-up, subjects with $\mathrm{mdMCI}^{-}$were more likely to progress to a non-AD dementia, and those with mdMCI ${ }^{+}$converted mostly to AD [21]. Conversely, data from an Austrian community birth cohort study found that, after thirty months of follow-up, the aMCI subtype evolved towards both AD and non-AD dementia and many patients developed $\mathrm{AD}$ from non amnestic MCI [42]. According to these as well as to previous data $[65,89,104,111]$, MCI appears to be an extremely heterogeneous clinical entity in terms of etiology, clinical presentation and outcome and much effort is needed for developing a more uniform diagnostic classification and better defined operational criteria.

\section{EPIDEMIOLOGY}

\section{Prevalence and Incidence of MCI}

Population-based studies in older adults (age $\geqslant 60$ or $\geqslant 65$ years) performed in North America and Europe reported a prevalence of MCI ranging from $11 \%$ to $17 \%[35,46,51,70,111]$, higher than previously reported prevalence of dementia $(6-8 \%)[35,51,70]$.

Prevalence of the aMCI subtype was estimated between 3 and 5\% [70,76]. Likewise, in the Canadian Study of Health and Aging, the prevalence of "circum- 
scribed memory loss" or "isolated memory deficit", a clinical construct similar to aMCI, was about 5\% [43]. Very few studies addressed this aspect in the oldest old population [104].

Regarding the incidence rates, the few studies published to date considered only the aMCI subtype, with a range from 9.9 to 21.5 per 1000 person per year in people older than 65 years $[65,120]$.

Most of the variability in prevalence and incidence estimates of MCI is probably due to the different operational criteria used rather than to the characteristics of the studied populations.

\section{Risk Factors for MCI}

Not many studies have prospectively addressed the role of putative risk factors for MCI. Three short-term longitudinal studies, carried out in subjects with MCI, identified as risk factors older age, low education, being African American, presence of apolipoprotein $\mathrm{E}$ $\varepsilon 4$ allele (ApoE 4), cortical atrophy at neuroimaging, signs or symptoms of vascular diseases and depression $[14,71,123]$. In a recent three-year prospective study, the authors found that a previous diagnosis of psychosis, hip fracture and polypharmacy increased the risk of cognitive impairment in non demented subjects, independent of subsequent development of dementia [89]. Furthermore, three long-term prospective studies described midlife alcohol drinking, elevated serum cholesterol, high diastolic blood pressure, ApoE $\varepsilon 4$, and white matter hyperintensities as risk factors for MCI in late life $[8,31,63]$.

Prevalence of vascular risk factors in different MCI subtypes was evaluated in more than two hundred subjects with MCI collected in the ReGAl project (Rete Geriatrica Alzheimer - Geriatric Network on Alzheimer's disease), the largest longitudinal Italian multicentric clinical-based study on aging and dementia, promoted by the Italian Society of Gerontology and Geriatrics (SIGG). This project, initiated in 2001 and still ongoing, involves 35 Geriatric Memory Clinics all over Italy and is coordinated by the Institute of Gerontology and Geriatrics of the University of Perugia. Methods of the ReGA1 project have been described in more detail elsewhere [106]. From the analysis of collected data, a different vascular risk profile among different MCI subtypes was found, with subjects with snmMCI having a higher prevalence of ischemic heart disease and of TIA/stroke, a higher Hachinski ischemic score, and a higher prevalence of white matter lesions on CT/MRI scan compared to aMCI (submitted paper). These data suggest that, as with dementia, the heterogeneity of clinical expression in different MCI subtypes is probably related to a different pathogenesis, that may include both degenerative and vascular factors.

\section{Mortality}

There is little information on mortality rate in MCI and in the different MCI subtypes. A prospective community study of the Mayo Clinic Group demonstrated an increased mortality in subjects with aMCI compared to normal control subjects over a six-year follow-up. Mortality was greater in mdMCI than in aMCI [56]. A recent review reported a non significant increase in mortality for subjects with MCI compared to cognitively intact subjects [51]. However, only few studies are available on this issue, and a comparison of the literature is problematic, due to variations in criteria and methodology.

\section{COGNITIVE STATUS}

Currently, the diagnosis of MCI is mainly based on results at neuropsychological tests. The large variability due to measurement errors, lack of appropriate normative data and difference in sensitivity and specificity of the neuropsychological batteries more commonly used, can cause misclassification. In the original MCI criteria, Petersen and collaborators [99] suggested a cut-off of at least 1.5 standard deviations below the ageand education-adjusted values for defining as "mild" the impairment in different cognitive domains. Among cognitive tasks, neuropsychological tests assessing delayed recall, executive functions and selective attention have been found to better predict the conversion of MCI to dementia [3,27,122], but with a sensitivity and specificity usually lower than $70 \%$ [88]. Conversely, it was recently shown that the performance at the CERAD-10-word list (CERAD-CWL), a task evaluating long-term verbal recall, was highly sensitive for detecting MCI [118]. Using correspondent analysis to derive a weighted score for each subject from their item responses over the three immediate- and one delayedrecall trials of the CERAD-CWL, the authors found that comparing MCI versus normal subjects, accuracy was $97 \%$, sensitivity $94 \%$ and specificity $89 \%$. For $\mathrm{MCI} / \mathrm{mild}$ dementia versus normal subjects, accuracy was $98 \%$, sensitivity $96 \%$ and specificity $91 \%$. 
Specific cognitive batteries for MCI have not been proposed yet, although there is a need for sensitive, user-friendly, MCI cognitive screening tests for clinicians. Recently, the Montreal Cognitive Assessment (MOCA) has been developed [93]. This test represents a brief cognitive screening tool with high sensitivity and specificity for detecting MCI, as currently conceptualized, in patients performing in the normal range on the Mini-Mental State Examination. With the same purpose, Li and collaborators [68] showed that using a brief instrument combining a single-item informant report of the memory problem and a four-item Instrumental Activities of Daily Living (IADL) scale, it is possible to differentiate MCI and mild AD from normal aging with high accuracy, sensitivity and specificity.

\section{FUNCTIONAL STATUS}

The original criteria for MCI provided for intact activities of daily living (ADL), but the current recommendations indicate that basic ADL (BADL) should be mainly preserved, and that a "minimal impairment" in instrumental ADL (IADL) may be accepted [129]. However, to date non specific instruments for evaluating complex activities of daily living in MCI have been proposed, and there is a need for a consensus regarding the degree of functional decline that can be considered acceptable in the frame of MCI definition [49]. Analyzing the functional characteristics of subjects with MCI collected in the ReGAl study, it was found that subjects with MCI had a more severe IADL disability than cognitively healthy elderly controls, particularly in shopping, self-administration of drugs, and in handling economy. These IADL disabilities were significantly associated with the degree of cognitive impairment, but not with the somatic comorbidity [40]. Consistent with these findings, Bennett and collaborators [18], in their study population of MCI, did not detect impairment in BADL while the IADL impairment was highly prevalent, with $53 \%$ of subjects needing help with housework and $43 \%$ with shopping. Similarly, in another study, it was found that MCI patients have limitations in everyday tasks that involve either memory (i.e. finding things at home, keeping appointments, and remembering information from a conversation or from television) or complex reasoning (i.e., checking the bank account, shopping, organizing travel), whereas they have normal abilities on basic ADL [97].

Furthermore, recent data suggest that the inclusion of IADL restriction in MCI criteria improves the pre- diction of a subsequent dementia as well as the stability of MCI condition over time [96]. Incorporating difficulties in performing the activities of daily living with the alterations in non-memory cognitive functions has been found to ameliorate the original diagnostic algorithm for MCI and better detect subjects at risk of convertion to dementia [11].

\section{NEUROPSYCHIATRIC SYMPTOMS}

Neuropsychiatric symptoms (NPS) have not been included in the diagnostic criteria and only recently some studies described the neuropsychiatric features of MCI $[24,39,44,48,57,73]$. According to these studies, frequency of NPS in MCI ranges from 35\% to 59\%, substantially mimicking the neuropsychiatric involvement of AD. In particular, anxiety-depressive symptoms, apathy, irritability and agitation appear to be the most common NPS in both conditions [39,73,74]. A similar spectrum of affective disorders was observed in subjects with MCI in the ReGAl project: depression and anxiety were, in fact, the most common symptoms, observed in about $33 \%$ of subjects, followed by apathy $(22 \%)$ and irritability (20\%). Their presence was associated with a more severe somatic comorbidity and functional disability, both in ADL and IADL [77].

Among affective disorders, depression has been described as a predictor for a subsequent cognitive decline $[15,131]$ and as an independent risk factor for the development of MCI [14]. Depression predicted a faster cognitive deterioration in subjects with aMCI, increasing the risk of conversion to dementia [87].

Recent data showed that a previous diagnosis of psychosis independently increases the risk of MCI [89]; furthermore MCI subjects who convert to $\mathrm{AD}$ have a higher frequency of apathy compared to nonconverters [113].

\section{NEUROPATHOLOGY}

Relatively few data on the neuropathological features of MCI are present in the literature. Results from the Religious Order Study showed that more than one half of persons with MCI met the National Institute on Aging-Reagan criteria for AD. However, about one third of them had also cerebral infarctions [17]. Similarly, in a recent study describing the neuropathological features of aMCI the authors found that many patients did not fulfil the neuropathologic criteria for AD 
but their pathologic findings showed characteristics of a transitional state of evolving AD. Although medial temporal lobe structures, as typical of subjects with $\mathrm{AD}$, were involved in all aMCI, they had also other concomitant pathologic abnormalities, including argyrophilic grain disease, hippocampal sclerosis, and vascular lesions [100]. Presence of neurofibrillary tangles rather than amyloid deposition seems to be more preminent in MCI compared to cognitively healthy controls, with the highest values in early AD. The numbers of neurofibrillary tangles in entorhinal cortex and hippocampus are related to the progressive memory loss. This suggests a continuum of neurofibrillary tangle pathologies underlying transition between normal aging, MCI and early AD [79].

\section{NEUROIMAGING}

Several neuroimaging studies described the structural and functional changes of subjects with MCI. The most consistent data derived from structural magnetic resonance imaging (MRI). Subjects with MCI show atrophy of the entorhinal and hippocampo-amygdala regions with an intermediate degree between that observed in normal aging and in AD [116]. Rusinek et al. [115] reported that the medial temporal lobe atrophy rate was the most significant predictor of conversion from normal aging to MCI, with $91 \%$ specificity and $85 \%$ sensitivity. In addition to hippocampal atrophy, alteration of parahippocampal white matter fibers has been suggested as contributing to memory decline in elderly individuals with MCI by partially disconnecting the hippocampus from incoming sensory information [121]. Concerning specific MCI subtypes, recent data show that mdMCI and aMCI have distinct brain structural abnormalities. While both groups have mesial temporal and cortical volume loss, those with aMCI have a more severe involvement of the mesial temporal structures and less of the neocortical heteromodal association cortices than mdMCI [16]. However, quantification of brain volumes has not been standardized for clinical use, and volumetric MRI is not currently included in the diagnostic work-up of MCI.

Compared to MRI, a small number of functional imaging studies have been conducted in MCI. Data obtained using [18F]-fluorodeoxyglucose positron emission tomography (FDG-PET) showed that the reduction in glucose metabolism in the hippocampus significantly improved diagnostic accuracy for MCI over
MRI hippocampal volumetric measures $(85 \%$ versus 73\%) [30].

There have been increasing efforts to develop diagnostic neuroimaging methods able to detect amyloid or tau proteins. Radiolabelled PET tracers, which bind to amyloid plaques and neurofibrillary tangles in vitro, have been a matter of intense investigation. A recent study conducted with 2-(1-\{6-[(2-[F-18]fluoroethyl) (methyl)amino]-2-naphthyl $\}$ ethylidene) malononitrile (FDDNP) PET showed that the global FDDNP binding (average of the values for temporal, parietal, posterior cingulated, and frontal regions) in MCI subjects was significantly higher than in controls and lower than in AD. These data suggest that FDDNP-PET is able to differentiate MCI from controls and $\mathrm{AD}$, probably more accurately than FDG-PET or volumetric MRI measures [119].

Another recent technique previously used in $\mathrm{AD}$ and then applied to MCI, is proton magnetic resonance spectroscopy $\left({ }^{1} \mathrm{H}-\mathrm{MRS}\right)$, a useful tool for the in vivo assessment of several biochemical compounds of the brain. Data from Catani and collaborators [23], showed that subjects with MCI had an alteration in myoInositol signal, with significantly higher value of myoInositol/Creatine ratio $(\mathrm{mI} / \mathrm{Cr})$ than control subjects and similar to subjects with mild $\mathrm{AD}$, who instead had a significant reduction of $N$-Acetyl-Aspartate/Creatine ratio $(\mathrm{NAA} / \mathrm{Cr})$ level in the paratrigonal white matter compared to controls. Consistently, Kantarci et al. [60] showed in the gray matter of posterior cingulate gyrus an increased $\mathrm{mI} / \mathrm{Cr}$ level in subjects with MCI compared to normal controls and higher still in patients with $\mathrm{AD}$, as well as a lower NAA/Cr in AD compared to both MCI and cognitively normal subjects. On the contrary, Chantal et al. [25] suggested that the increased $\mathrm{mI}$ signal is a neurochemical abnormality associated with AD but not with MCI, with a significant increased $\mathrm{mI}$ signal in patients with AD compared to both MCI and control subjects.

\section{BIOMARKERS}

Biomarkers other than those obtained from structural or functional neuroimaging were widely studied in subjects with early AD. Typical neuropathological lesions of $\mathrm{AD}$ are senile plaques, constituted by the beta-amyloid protein, and neurofibrillary tangles, originating from hyperphosphorylated tau protein [5]. Over the last years, many efforts have been made in the identification of potential biomarkers for both MCI and de- 
mentia from the analysis of cerebral spinal fluid (CSF). CSF biomarkers for MCI include total tau protein (T$\tau)$, phosphorylated tau protein $(\mathrm{P}-\tau)$ and amyloid beta $1-42$ protein $(\mathrm{A} \beta-42)[5,116]$. Several studies have found high CSF T- $\tau$ and $\mathrm{P}-\tau$, and low CSF A $\beta-42$ in subjects with MCI, with sensitivity figures similar to, or slightly lower than, those found in AD cases $[6,7,9$, 66].

These biomarkers also showed a high sensitivity in differentiating early $\mathrm{AD}$ from normal aging, depression and Parkinson's disease, but lower specificity versus other dementias, such as fronto-temporal and Lewy body dementia [5].

Recently, it was suggested that also plasma $\mathrm{A} \beta-42 /$ A $\beta$-40 ratio may be a useful marker for identifying cognitively healthy elderly subjects who are at increasing risk for developing $\mathrm{MCI}$ and $\mathrm{AD}$, reflecting the extent to which there has been selective aggregation and deposition of $\mathrm{A} \beta-42$ in the brain [50]. The authors postulated that CSF $\mathrm{A} \beta-42$, as well as plasma $\mathrm{A} \beta-42$ levels, decline in parallel as $\mathrm{A} \beta-42$ deposits in the brain, and, because $\mathrm{A} \beta-42$ aggregation and deposition precedes $\mathrm{MCI}$ and $\mathrm{AD}$, most subjects who develop $\mathrm{MCI} / \mathrm{AD}$ have a low $\mathrm{A} \beta-42 / \mathrm{A} \beta-40$ ratio several years before the diagnosis of the disease.

There is also evidence for a role of oxidative stress in the pathogenesis of MCI $[22,62,78,83,107]$. Increased levels of the isoprostane 8,12 -iso-PF2a-VI -a specific marker of in vivo lipid peroxidation [108] - were found to be significantly elevated in CSF, plasma and urine of MCI subjects compared with controls [107], suggesting that lipid peroxidation may be an early event in the pathogenesis of the disease. Nevertheless, additional studies on the presence of elevated levels of biomarkers of oxidative stress in MCI are warranted, also in light of the discrepancies otherwise observed between brain/CSF versus plasma/urine F2-isoprostanes and F4-neuroprostanes levels [90,109].

An increased DNA oxidative damage in peripheral leukocytes, previously reported in AD subjects [81,82], has been recently found in MCI [85], as well as in nuclear and mitochondrial DNA isolated from frontal, parietal and temporal brain lobes [127].

Subjects with MCI showed also lower levels of non enzymatic antioxidants (vitamin A, vitamin C, vitamin E, uric acid and of the carotenoids lutein, zeaxanthin and $\beta$-carotene) and lower activities of enzymatic antioxidants (plasma and erythrocyte superoxide dismutase, plasma glutathione peroxidase) as compared to controls [110]. Similarly, plasma total antioxidant capacity (including uric acid, glutathione, thiol groups, vitamins, glutathione peroxidase, superoxide dismutase and catalase) was shown to be significantly reduced in MCI subjects as compared to age-matched controls [53].

Finally, it was recently found a decrease in the percentage of total lymphocytes and a concomitant increase in granulocytes in MCI subjects compared to controls [75], consistent with evidences of a decrease in the proliferative ability of lymphocytes [117], and of increased granulocyte activity [69] in AD patients, suggesting an inflammatory state specific not only for $\mathrm{AD}$, but also for MCI.

\section{PREDICTORS OF PROGRESSION OF MCI TO DEMENTIA}

Clinical, imaging, genetic and CSF aspects have been widely examined as possible markers in MCI in order to detect subjects at greater risk of conversion to dementia. However, most of the studies describe subjects with aMCI, with negligible information for other MCI subtypes. Some authors have also tried to combine different predictors to increase the accuracy of conversion to AD or other dementias.

Neuropsychological predictors of conversion include performance on specific cognitive tests, particularly those assessing delayed recall and executive functions [3,27,122]. However, neuropsychological tests rarely overcome $70 \%$ sensitivity and specificity [88]. Conversely, Visser an colleagues [126] found that scores on memory tests predicted progression to AD with $88 \%$ accuracy, and the addition of hippocampal volume measure increased accuracy to $100 \%$. Other clinical aspects considered as predictors of conversion are IADL disability [96], depressive symptoms [87], and coexistent motor dysfunctions. For this aspect, in a recent longitudinal cohort study in subjects with MCI, impaired motor performance of lower limbs, parkinsonian gait, and bradykinesia increased the risk of $\mathrm{AD}$ after a ten-year follow-up [1].

Hippocampal or entorhinal atrophy on MRI are the most commonly used neuroradiological markers of conversion from MCI to dementia [116]. Subjects with MCI who converted to AD during two-year follow-up, in fact, had a greater atrophy in the left entorhinal cortex, bilateral superior temporal gyri, and right inferior frontal gyrus compared to nonconverters [16]. Similarly, data from the Rotterdam study showed that hippocampal and amygdala volumes were strongly asso- 
ciated with the risk of dementia in cognitively intact elderly people after six-year follow-up [33].

Recent promising neuroimaging techniques for evaluating conversion from MCI to dementia include PET and ${ }^{1} \mathrm{H}$-MRS. Reduced metabolic activity in temporoparietal cortices [10] or in the posterior cingulate gyrus [36], as shown in FDG-PET scans, have been associated with a greater risk of progression to dementia. Further, the highest degree of accuracy (>90\%) was achieved by means of PET scan plus either memory performance [4] or APOE $\varepsilon 4$ genotype [92].

A recent study performed with ${ }^{1} \mathrm{H}-\mathrm{MRS}$ found that subjects with aMCI who convert to AD over one year had a significant difference of the NAA/Cr ratio in the left hemisphere with respect to both non-converters and healthy controls [84]. These data confirmed previous evidence suggesting that decreased NAA/Cr levels predict future conversion to AD in subjects with MCI [26, 86]. It was recently reported that while there were no differences in $\mathrm{NAA} / \mathrm{Cr}$, $\mathrm{Cho} / \mathrm{Cr}$ and $\mathrm{mI} / \mathrm{Cr}$ at baseline between stable MCI and MCI who converted to AD after a median follow-up period of thirteen months, the annualized rate of change in $\mathrm{Cho} / \mathrm{Cr}$ ratio was greater in stable MCI compared to converter MCI and cognitively normal controls, suggesting a possible compensatory mechanism in stable MCI [61].

CSF biomarkers represent to date those with the highest accuracy for the conversion from MCI to AD. Three biomarkers $-\mathrm{T}-\tau$ protein, $\mathrm{P}-\tau$ protein and $\mathrm{A} \beta-42$ protein - have been evaluated in many scientific reports. Subjects with MCI who lately developed AD had an increased baseline CSF concentration of T- $\tau$ and $\mathrm{P}-\tau$, whereas the level of $\mathrm{A} \beta-42$ protein was decreased. In addition, recent studies provided evidence that reduction in the $\mathrm{A} \beta-42 / \mathrm{P}-\tau$ ratio may help to identify those patients with MCI who later develop AD $[5,116]$. However, the clinical follow-up in these studies has been short and data have been collected in small selected hospital samples. To overcome this issue, data from a recent article, carried out in 180 consecutive individuals with MCI over a four- to six-year of follow-up, showed that subjects with MCI who had pathological concentrations of $\mathrm{T}-\tau$ and $\mathrm{A} \beta-42$ proteins at baseline are at increased risk to develop AD. The association between pathological CSF findings and progression to AD was independent of APOE genotype, age, gender, and education. The combination of T- $\tau$ and $\mathrm{A} \beta-42 / \mathrm{P}-\tau$ ratio yielded closely similar results with a sensitivity of $95 \%$ and a specificity of $87 \%$ [55]. CSF T- $\tau / \mathrm{A} \beta$ 42 and $\mathrm{P}-\tau / \mathrm{A} \beta-42$ ratios were recently identified as good biomarkers that predict future dementia also in cognitively healthy old subjects [37].
Some studies have tried to identify non-CSF peripheral markers of MCI. Among those, platelet forms of amyloid precursor protein have been proposed. At two-year follow-up MCI subjects who converted to AD showed a significant decrease of baseline platelet APP forms ratio compared to nonconverters, with a sensitivity of $83 \%$ and a specificity of $71 \%$ [20].

Among genetic predictors, the APOE $\varepsilon 4$ allele, the only genetic factor associated with an increased risk of sporadic AD [38], was described to be associated with conversion from MCI to dementia. Data from the Mayo Clinic cohort, which is a relatively young group, demonstrated that APOE $\varepsilon 4$ genotype is the best predictor of conversion to dementia [101]. These findings were recently confirmed by a longitudinal cohort study in which the presence of at least one APOE $\varepsilon 4$ allele affected the transition from cognitively normal aging into amnestic MCI or into dementia [64]. According to these data, APOE $\varepsilon 4$ may represent a predictor of dementia only for aMCI but not for other MCI subtypes.

\section{TREATMENT AND PREVENTION}

Early treatment of mild to moderate AD is associated with a better response than late treatment [130], so it is conceivable that treating MCI may be most effective in delaying progression to AD. However, to date there is no proven pharmacological approach for MCI. Antioxidants, including Ginkgo Biloba, selegiline and vitamin E, have been proposed for delaying the progression to dementia, but their usefulness is unclear [80]. In randomized clinical trials, cholinesterase inhibitors (donepezil, rivastigmine, and galantamine), antioxidant (vitamin E), anti-inflammatory drugs (rofecoxib), and nootropics (piracetam) failed to prevent progression of MCI to dementia [58]. In a randomized clinical trial of three years of observation, donepezil showed a transient preventive effect after one year, particularly in subjects who had at least one APOE $\varepsilon 4$ allele, but efficacy was lost at the end of the study [102], so evidence is not strong enough for recommending its routine use [114].

Management of subjects with MCI is currently non specific: control of vascular risk factors, treatment of a concomitant condition such as depression or hypothyroidism, and reduction in the use of anticholinergic drugs have been proposed [47]. Epidemiological data suggests that moderate exercise and physical activity, such as walking three times a week, are associated with a lower risk of dementia [105]. According to these findings, a randomized controlled trial examining the effect 
of a walking program and vitamin B supplementation on the rate of cognitive decline in older adults with MCI is currently ongoing [124]. In addition, recent data suggest that an active and socially integrated lifestyle in late life protects against dementia and $\mathrm{AD}$ [45]. In the Bronx Aging Study, participation in cognitive activities was associated with a lower risk of development of MCI, even after excluding individuals at early stages of dementia [125]. Since it seems evident that memory and attention training is beneficial in normal elderly persons [13] and in patients with early AD [29], cognitive training may have a role in subjects with MCI in slowing down further decline and should be explored in future clinical trials. Encouraging results, in fact, have been reported from uncontrolled studies [54]. Finally, clinicians should pay close attention to control for modifiable cardiovascular risk factors, including blood pressure, diabetes, and lipid profile, all factors that have been associated with an increased risk of dementia.

\section{CONCLUSIONS}

MCI is a syndrome at high risk for dementia and not a definitive diagnosis of a disease. It represents a condition with multiple sources of heterogeneity, including clinical presentation, etiology, and prognosis. The majority of data present in the literature refer to aMCI and very few concern other subtypes of the condition. According to these data, aMCI seems to represent an early stage of $\mathrm{AD}$, while the outcomes of the other MCI forms are more heterogeneous.

It might be time to consider revisions of the ICD and DSM to include specific diagnostic criteria for MCI. Furthermore, an update of the NINCDS-ADRDA criteria for $\mathrm{AD}$ should include a prodromal stage of Alzheimer's disease that defines MCI. Current criteria for MCI should be updated to include restriction in complex ADL. There is a need for sensitive tools able to detect subtle modification in cognitive and functional abilities also to implement a primary prevention trial in non demented subjects. With this aim the Alzheimer's Disease Cooperative Study Instrument Committee has recently developed new assessment instruments that can be self-administered and/or do not require significant involvement of professional staff [41].

The diagnostic and prognostic role of specific behavioral symptoms (i.e. depression), somatic conditions and motor dysfunctions need to be better clarified. There is not enough evidence to recommend specific predictors for the conversion from MCI to AD. The combined use of cognitive tests, APOE genotype, and neuroimaging techniques is probably the best option for prediction purposes, but further studies are needed to define the sensitivity and specificity of this global approach for recommending its routine use at the screening level.

\section{ACKNOWLEDGEMENTS}

Authors thank Mrs. Joan Ireland Orfei for the English revision of the manuscript.

The ReGAl project of the Italian Society of Gerontology and Geriatrics (SIGG) was partially supported by the Italian Ministry of Health (Alfa Project) and by an unrestricted grant from Novartis Pharma Italia.

\section{References}

[1] N.T. Aggarwal, R.S. Wilson, T.L. Beck, J.L. Bienias and D.A. Bennett, Motor dysfunction in mild cognitive impairment and the risk of incident Alzheimer disease, Arch Neurol 63 (2006), 1763-1769.

[2] American Psychiatric Association, Diagnostic and statistical manual (4th edn), American Psychiatric Association, Washington, 1994.

[3] H. Amieva, L. Letenneur, J.F. Dartigues, I. Rouch-Leroyer, C. Sourgen, F. D'Alchee-Biree, M. Dib, P. Barberger-Gateau, J.M. Orgogozo and C. Fabrigoule, Annual rate and predictors of conversion to dementia in subjects presenting mild cognitive impairment criteria defined according to a populationbased study, Dement Geriatr Cogn Disord 18 (2004), 87-93.

[4] D. Anchisi, B. Borroni, M. Franceschi, N. Kerrouche, E. Kalbe, B. Beuthien-Beumann, S. Cappa, O. Lenz, S. Ludecke, A. Marcone, R. Mielke, P. Ortelli, A. Padovani, O. Pelati, A. Pupi, E. Scarpini, S. Weisenbach, K. Herholz, E. Salmon, V. Holthoff, S. Sorbi, F. Fazio and D. Perani, Heterogeneity of brain glucose metabolism in mild cognitive impairment and clinical progression to Alzheimer disease, Arch Neurol 62 (2005), 1728-1733.

[5] N. Andreasen and K. Blennow, CSF biomarkers for mild cognitive impairment and early Alzheimer's disease, Clin Neurol Neurosurg 107 (2005), 165-173.

[6] N. Andreasen, L. Minthon, E. Vanmechelen, H. Vanderstichele, P. Davidsson, B. Winblad, and K. Blennow, Cerebrospinal fluid tau and Abeta42 as predictors of development of Alzheimer's disease in patients with mild cognitive impairment, Neurosci Lett 273 (1999), 5-8.

[7] N. Andreasen, E. Vanmechelen, H. Vanderstichele, P. Davidsson and K. Blennow, Cerebrospinal fluid levels of total-tau, phospho-tau and A beta 42 predicts development of Alzheimer's disease in patients with mild cognitive impairment, Acta Neurol Scand Suppl 179 (2003), 47-51.

[8] T. Anttila, E.L. Helkala, M. Viitanen, I. Kareholt, L. Fratiglioni, B. Winblad, H. Soininen, J. Tuomilehto, A. Nissinen and M. Kivipelto, Alcohol drinking in middle age and subsequent risk of mild cognitive impairment and dementia in old age: a prospective population based study, BMJ 329 (2004), 539. 
[9] H. Arai, K. Ishiguro, H. Ohno, M. Moriyama, N. Itoh, N. Okamura, T. Matsui, Y. Morikawa, E. Horikawa, H. Kohno, H. Sasaki and K. Imahori, CSF phosphorylated tau protein and mild cognitive impairment: a prospective study, Exp Neurol 166 (2000), 201-203.

[10] E. Arnaiz, V. Jelic, O. Almkvist, L.O. Wahlund, B. Winblad, S. Valind and A. Nordberg, Impaired cerebral glucose metabolism and cognitive functioning predict deterioration in mild cognitive impairment, Neuroreport 12 (2001), 851855.

[11] S. Artero, R. Petersen, J. Touchon and K. Ritchie, Revised criteria for mild cognitive impairment: validation within a longitudinal population study, Dement Geriatr Cogn Disord 22 (2006), 465-470.

[12] L. Backman, S. Jones, A.K. Berger, E.J. Laukka and B.J. Small, Multiple cognitive deficits during the transition to Alzheimer's disease, J Intern Med 256 (2004), 195-204.

[13] K. Ball, D.B. Berch, K.F. Helmers, J.B. Jobe, M.D. Leveck, M. Marsiske, J.N. Morris, G.W. Rebok, D.M. Smith, S.L. Tennstedt, F.W. Unverzagt and S.L. Willis, Effects of cognitive training interventions with older adults: a randomized, controlled trial, JAMA 288 (2002), 2271-2281.

[14] D.E. Barnes, G.S. Alexopoulos, O.L. Lopez, J.D. Williamson and K. Yaffe, Depressive symptoms, vascular disease, and mild cognitive impairment: findings from the Cardiovascular Health Study, Arch Gen Psychiatry 63 (2006), 273-279.

[15] S.S. Bassuk, L.F. Berkman and D. Wypij, Depressive symptomatology and incident cognitive decline in an elderly community sample, Arch Gen Psychiatry 55 (1998), 1073-1081.

[16] S. Bell-McGinty, O.L. Lopez, C.C. Meltzer, J.M. Scanlon, E.M. Whyte, S.T. Dekosky and J.T. Becker, Differential cortical atrophy in subgroups of mild cognitive impairment, Arch Neurol 62 (2005), 1393-1397.

[17] D.A. Bennett, J.A. Schneider, J.L. Bienias, D.A. Evans and R.S. Wilson, Mild cognitive impairment is related to Alzheimer disease pathology and cerebral infarctions, $\mathrm{Neu}$ rology 64 (2005), 834-841.

[18] H.P. Bennett, O. Piguet, D.A. Grayson, H. Creasey, L.M. Waite, T. Lye, A.J. Corbett, M. Hayes, G.A. Broe and G.M. Halliday, Cognitive, extrapyramidal, and magnetic resonance imaging predictors of functional impairment in nondemented older community dwellers: the Sydney Older Person Study, $J$ Am Geriatr Soc 54 (2006), 3-10.

[19] R.C. Blackford and A. La Rue, Criteria for diagnosing age associated memory impairment: proposed improvements in the field, Dev Neuropsychol 5 (1989), 295-306.

[20] B. Borroni, F. Colciaghi, C. Caltagirone, L. Rozzini, L. Broglio, F. Cattabeni, M. Di Luca and A. Padovani, Platelet amyloid precursor protein abnormalities in mild cognitive impairment predict conversion to dementia of Alzheimer type: a 2-year follow-up study, Arch Neurol 60 (2003), 17401744 .

[21] A. Busse, A. Hensel, U. Guhne, M.C. Angermeyer and S.G. Riedel-Heller, Mild cognitive impairment: long-term course of four clinical subtypes, Neurology 67 (2006), 2176-2185.

[22] D.A. Butterfield, T. Reed, M. Perluigi, C. De Marco, R. Coccia, C. Cini and R. Sultana, Elevated protein-bound levels of the lipid peroxidation product, 4-hydroxy-2-nonenal, in brain from persons with mild cognitive impairment, Neurosci Lett 397 (2006), 170-173.

[23] M. Catani, A. Cherubini, R. Howard, R. Tarducci, G.P. Pelliccioli, M. Piccirilli, G. Gobbi, U. Senin and P. Mecocci, 1H MR spectroscopy differentiates mild cognitive impairment from normal brain aging, Neuroreport 12 (2001), 2315-2317.
[24] D.C. Chan, J.D. Kasper, B.S. Black and P.V. Rabins, Prevalence and correlates of behavioral and psychiatric symptoms in community-dwelling elders with dementia or mild cognitive impairment: the Memory and Medical Care Study, Int J Geriatr Psychiatry 18 (2003), 174-182.

[25] S. Chantal, C.M. Braun, R.W. Bouchard, M. Labelle and Y. Boulanger, Similar 1H magnetic resonance spectroscopic metabolic pattern in the medial temporal lobes of patients with mild cognitive impairment and Alzheimer disease, Brain Res 1003 (2004), 26-35.

[26] L.L. Chao, N. Schuff, J.H. Kramer, A.T. Du, A.A. Capizzano, J. O'Neill, O.M. Wolkowitz, W.J. Jagust, H.C. Chui, B.L. Miller, K. Yaffe and M.W. Weiner, Reduced medial temporal lobe $\mathrm{N}$-acetylaspartate in cognitively impaired but nondemented patients, Neurology 64 (2005), 282-289.

[27] P. Chen, G. Ratcliff, S.H. Belle, J.A. Cauley, S.T. DeKosky and M. Ganguli, Cognitive tests that best discriminate between presymptomatic $\mathrm{AD}$ and those who remain nondemented, Neurology 55 (2000), 1847-1853.

[28] T. Crook, R.T. Bartus and S.H. Ferris, Age associated memory impairment: proposed diagnostic criteria and measures of clinical change: report of a National Institute of Mental Health Work Group, Dev Neuropsychol 2 (1986), 261-276.

[29] R.N. Davis, P.J. Massman and R.S. Doody, Cognitive intervention in Alzheimer disease: a randomized, placebocontrolled study, Alzheimer Dis Assoc Disord 15 (2001), 1-9.

[30] S. De Santi, M.J. de Leon, H. Rusinek, A. Convit, C.Y. Tarshish, A. Roche, W.H. Tsui, E. Kandil, M. Boppana, K. Daisley, G.J. Wang, D. Schlyer and J. Fowler, Hippocampal formation glucose metabolism and volume losses in MCI and AD, Neurobiol Aging 22 (2001), 529-539.

[31] C. DeCarli, B.L. Miller, G.E. Swan, T. Reed, P.A. Wolf and D. Carmelli, Cerebrovascular and brain morphologic correlates of mild cognitive impairment in the National Heart, Lung, and Blood Institute Twin Study, Arch Neurol 58 (2001), 643647.

[32] C. DeCarli, Mild cognitive impairment: prevalence, prognosis, aetiology, and treatment, Lancet Neurol 2 (2003), 15-21.

[33] T. den Heijer, M.I. Geerlings, F.E. Hoebeek, A. Hofman, P.J. Koudstaal and M.M. Breteler, Use of hippocampal and amygdalar volumes on magnetic resonance imaging to predict dementia in cognitively intact elderly people, Arch Gen Psychiatry 63 (2006), 57-62.

[34] D. De Ronchi, D. Berardi, M. Menchetti, G. Ferrari, A. Serretti, E. Dalmonte and L. Fratiglioni, Dement Geriatr Cogn Disord 19 (2005), 97-105.

[35] A. Di Carlo, M. Baldereschi, L. Amaducci, S. Maggi, F. Grigoletto, G. Scarlato and D. Inzitari, Cognitive impairment without dementia in older people: prevalence, vascular risk factors, impact on disability. The Italian Longitudinal Study on Aging, J Am Geriatr Soc 48 (2000), 775-782.

[36] A. Drzezga, N. Lautenschlager, H. Siebner, M. Riemenschneider, F. Willoch, S. Minoshima, M. Schwaiger and A. Kurz, Cerebral metabolic changes accompanying conversion of mild cognitive impairment into Alzheimer's disease: a PET follow-up study, Eur J Nucl Med Mol Imaging 30 (2003), 1104-1113

[37] A.M. Fagan, C.M. Roe, C. Xiong, M.A. Mintun, J.C. Morris and D.M. Holtzman, Cerebrospinal Fluid tau/betaAmyloid42 Ratio as a Prediction of Cognitive Decline in Nondemented Older Adults, Arch Neurol 64 (2007), 343349.

[38] L.A. Farrer, L.A. Cupples, J.L. Haines, B. Hyman, W.A. Kukull, R. Mayeux, R.H. Myers, M.A. Pericak-Vance, N. 
Risch and C.M. van Duijn, Effects of age, sex, and ethnicity on the association between apolipoprotein $\mathrm{E}$ genotype and Alzheimer disease. A meta-analysis. APOE and Alzheimer Disease Meta Analysis Consortium, JAMA 278 (1997), 1349-1356.

[39] H. Feldman, P. Scheltens, E. Scarpini, N. Hermann, P. Mesenbrink, L. Mancione, S. Tekin, R. Lane and S. Ferris, Behavioral symptoms in mild cognitive impairment, Neurology $\mathbf{6 2}$ (2004), 1199-1201.

[40] F.T. Feliziani, E. Mariani, S. Ercolani, M. Caputo, P. Rinaldi, R. Monastero, U. Senin and P. Mecocci, Functional decline in Mild Cognitive Impairment. Results from the ReGAl project, $10^{\text {th }}$ ICAD, Madrid, July 15-20, 2006 [poster].

[41] S.H. Ferris, P.S. Aisen, J. Cummings, D. Galasko, D.P. Salmon, L. Schneider, M, Sano, P.J. Whitehouse, S. Edland and A.L. Thal for the Alzheimer's Disease Cooperative Study Group, ADCS Prevention Instrument Project: Overview and Initial Results, Alzheimer Dis Assoc Disord 20 (2006), S109S123.

[42] P. Fischer, S. Jungwirth, S. Zehetmayer, S. Weissgram, S. Hoenigschnabl, E. Gelpi, W. Krampla and K.H. Tragl, Conversion from subtypes of mild cognitive impairment to Alzheimer dementia, Neurology 68 (2007), 288-291.

[43] J.D. Fisk, H.R. Merry and K. Rockwood, Variations in case definition affect prevalence but not outcomes of mild cognitive impairment, Neurology 61 (2003), 1179-1184.

[44] Y. Forsell, K. Palmer and L. Fratiglioni, Psychiatric symptoms/syndromes in elderly persons with mild cognitive impairment. Data from a cross-sectional study, Acta Neurol Scand Suppl 179 (2003), 25-28.

[45] L. Fratiglioni, S. Paillard-Borg and B. Winblad, An active and socially integrated lifestyle in late life might protect against dementia, Lancet Neurol 3 (2004), 343-353.

[46] M. Ganguli, H.H. Dodge, C. Shen and S.T. DeKosky, Mild cognitive impairment, amnestic type: an epidemiologic study, Neurology 63 (2004), 115-121.

[47] S. Gauthier, B. Reisberg, M. Zaudig, R.C. Petersen, K. Ritchie, K. Broich, S. Belleville, H. Brodaty, D. Bennett, H. Chertkow, J.L. Cummings, M. de Leon, H. Feldman, M. Ganguli, H. Hampel, P. Scheltens, M.C. Tierney, P. Whitehouse and B. Winblad, International Psychogeriatric Association Expert Conference on mild cognitive impairment, Mild cognitive impairment, Lancet 367 (2006), 1262-1270.

[48] Y.E. Geda, G.E. Smith, D.S. Knopman, B.F. Boeve, E.G. Tangalos, R.J. Ivnik, D.A. Mrazek, S.D. Edland and R.C. Petersen, De novo genesis of neuropsychiatric symptoms in mild cognitive impairment (MCI), Int Psychogeriatr 16 (2004), 51-60.

[49] D.M. Geslani, M.C. Tierney, N. Herrmann and J.P. Szalai, Mild cognitive impairment: an operational definition and its conversion rate to Alzheimer's disease, Dement Geriatr Cogn Disord 19 (2005), 383-389.

[50] N.R. Graff-Radford, J.E. Crook, J. Lucas, B.F. Boeve, D.S. Knopman, R.J. Ivnik, G.E. Smith, L.H. Younkin, R.C. Petersen and S.G. Younkin, Association of low plasma Abeta42/Abeta40 ratios with increased imminent risk for mild cognitive impairment and Alzheimer disease, Arch Neurol 64 (2007), 354-362.

[51] J.E. Graham, K Rockwood, B.L. Beattie, R. Eastwood, S. Gauthier, H. Tuokko and I. McDowell, Prevalence and severity of cognitive impairment with and without dementia in an elderly population, Lancet 349 (1997), 1793-1796.

[52] U. Guehne, M.C. Angermeyer and S. Riedel-Heller, Is mortality increased in mildly cognitively impaired individuals?
A systematic literature review, Dement Geriatr Cogn Disord 21 (2006), 403-410.

[53] I. Guidi, D. Galimberti, S. Lonati, C. Novembrino, F. Bamonti, M. Tiriticco, C. Fenoglio, E. Venturelli, P. Baron, N. Bresolin and E. Scarpini, Oxidative imbalance in patients with mild cognitive impairment and Alzheimer's disease, Neurobiol Aging 27 (2006), 262-269.

[54] V.K. Gunther, P. Schafer, B.J. Holzner and G.W. Kemmler, Long-term improvements in cognitive performance through computer-assisted cognitive training: a pilot study in a residential home for older people, Aging Ment Health 7 (2003), 200-206.

[55] O. Hansson, H. Zetterberg, P. Buchhave, E. Londos, K. Blennow and L. Minthon, Association between CSF biomarkers and incipient Alzheimer's disease in patients with mild cognitive impairment: a follow-up study, Lancet Neurol 5 (2006), 228-234.

[56] A.L. Hunderfund, R.O. Roberts, T.C. Slusser, C.L. Leibson, Y.E. Geda, R.J. Ivnik, E.G. Tangalos and R.C. Petersen, Mortality in amnestic mild cognitive impairment: a prospective community study, Neurology 67 (2006), 1764-1768.

[57] T.J. Hwang, D.L. Masterman, F. Ortiz, L.A. Fairbanks and J.L. Cummings, Mild cognitive impairment is associated with characteristic neuropsychiatric symptoms, Alzheimer Dis Assoc Disord 18 (2004), 17-21.

[58] V. Jelic, M. Kivipelto and B. Winblad, Clinical trials in mild cognitive impairment: lessons for the future, J Neurol Neurosurg Psychiatry 77 (2006), 429-438.

[59] B. Johansson and S.H. Zarit, Early cognitive markers of the incidence of dementia and mortality: a longitudinal population-based study of the oldest old, Int J Geriatr Psychiatr 12 (1997), 53-59.

[60] K. Kantarci, C.R. Jack Jr, Y.C. Xu, N.G. Campeau, P.C. O'Brien, G.E. Smith, R.J. Ivnik, B.F. Boeve, E. Kokmen, E.G. Tangalos and R.C. Petersen, Regional metabolic patterns in mild cognitive impairment and Alzheimer's disease: A 1H MRS study, Neurology 55 (2000), 210-217.

[61] K. Kantarci, S.D. Weigand, R.C. Petersen, B.F. Boeve, D.S. Knopman, J. Gunter, D. Reyes, M Shiung, P.C. O'Brien, G.E. Smith, R.J. Ivnik, E.G. Tangalos and C.R. Jack Jr, Longitudinal (1)H MRS changes in mild cognitive impairment and Alzheimer's disease, Neurobiol Aging (2006), [Epub ahead of print].

[62] J.N. Keller, F.A. Schmitt, S.W. Scheff, Q. Ding, Q. Chen, D.A. Butterfield and W.R. Markesbery, Evidence of increased oxidative damage in subjects with mild cognitive impairment, Neurology 64 (2005), 1152-1156.

[63] M. Kivipelto, E.L. Helkala, T. Hanninen, M.P. Laakso, M. Hallikainen, K. Alhainen, H. Soininen, J. Tuomilehto and A. Nissinen, Midlife vascular risk factors and late-life mild cognitive impairment: A population-based study, Neurology 56 (2001), 1683-1689.

[64] R.J. Kryscio, F.A. Schmitt, J.C. Salazar, M.S. Mendiondo and W.R. Markesbery, Risk factors for transitions from normal to mild cognitive impairment and dementia, Neurology $\mathbf{6 6}$ (2006), 828-832.

[65] S. Larrieu, L. Letenneur, J.M. Orgogozo, C. Fabrigoule, H. Amieva, N. Le Carret, P. Barberger-Gateau and J.F. Dartigues, Incidence and outcome of mild cognitive impairment in a population-based prospective cohort, Neurology 59 (2002), 1594-1599.

[66] N.T. Lautenschlager, M. Riemenschneider, A. Drzezga and A.F. Kurz, Primary degenerative mild cognitive impairment: 
study population, clinical, brain imaging and biochemical findings, Dement Geriatr Cogn Disord 12 (2001), 379-386.

[67] R. Levy, Aging-associated cognitive decline. Working Party of the International Psychogeriatric Association in collaboration with the World Health Organization, Int Psychogeriatr 6 (1994), 63-68.

[68] M. Li, T.P. Ng, E.H. Kua and S.M. Ko, Brief informant screening test for mild cognitive impairment and early Alzheimer's disease, Dement Geriatr Cogn Disord 21 (2006), 392-402.

[69] F. Licastro, M.C. Morini, L.J. Davis, P. Malpassi, D. Cucinotta, R. Parente, C. Melotti and G. Savorani, Increased chemiluminescence response of neutrophils from the peripheral blood of patients with senile dementia of the Alzheimer's type, J Neuroimmunol 51 (1994), 21-26.

[70] O.L. Lopez, W.J. Jagust, S.T. DeKosky, J.T. Becker, A. Fitzpatrick, C. Dulberg, J. Breitner, C. Lyketsos, B. Jones, C. Kawas, M. Carlson and L.H. Kuller, Prevalence and classification of mild cognitive impairment in the Cardiovascular Health Study Cognition Study: part 1, Arch Neurol 60 (2003), 1385-1389.

[71] O.L. Lopez, W.J. Jagust, C. Dulberg, J.T. Becker, S.T. DeKosky, A. Fitzpatrick, J. Breitner, C. Lyketsos, B. Jones, C. Kawas, M. Carlson and L.H. Kuller, Risk factors for mild cognitive impairment in the Cardiovascular Health Study Cognition Study: part 2, Arch Neurol 60 (2003), 1394-1399.

[72] C.A. Luis, D.A. Loewenstein, A. Acevedo, W.W. Barker and R. Duara, Mild cognitive impairment: directions for future research, Neurology 61 (2003), 438-444.

[73] C.G. Lyketsos, O. Lopez, B. Jones, A.L. Fitzpatrick, J. Breitner and S. DeKosky, Prevalence of neuropsychiatric symptoms in dementia and mild cognitive impairment: results from the cardiovascular health study, JAMA 288 (2002), 1475-1483.

[74] C.G. Lyketsos, M. Steinberg, J.T. Tschanz, M.C. Norton, D.C. Steffens and J.C. Breitner, Mental and behavioral disturbances in dementia: findings from the Cache County Study on Memory in Aging, Am J Psychiatry 157 (2000), 708-714.

[75] S. Magaki, S.M. Yellon, C. Mueller and W.M. Kirsch, Immunophenotypes in the circulation of patients with mild cognitive impairment, J Psychiatr Res (2007), doi:10.1016/j.jpsychires.2007.01.004.

[76] J.J. Manly, S. Bell-McGinty, M.X. Tang, N. Schupf, Y. Stern and R. Mayeux, Implementing diagnostic criteria and estimating frequency of mild cognitive impairment in an urban community, Arch Neurol 62 (2005), 1739-1746.

[77] E. Mariani, S. Ercolani, M. Caputo, P. Rinaldi, R. Monastero, U. Senin and P. Mecocci, Amnestic Mild Cognitive Impairment or very mild Alzheimer's disease? Results from the ReGAl project, 10th ICAD, Madrid, July 15-20, 2006, [poster].

[78] E. Mariani, M.C. Polidori, A. Cherubini and P. Mecocci, Oxidative stress in brain aging, neurodegenerative and vascular diseases: an overview, J Chromatogr B 827 (2005), 65-75.

[79] W.R. Markesbery, F.A. Schmitt, R.J. Kryscio, D.G. Davis, C.D. Smith and DR. Wekstein, Neuropathologic substrate of mild cognitive impairment, Arch Neurol 63 (2006), 38-46.

[80] P. Mecocci, E. Mariani, V. Cornacchiola and M.C. Polidori, Antioxidant for the treatment of Mild Cognitive Impairment, Neurol Res 26 (2004), 588-602.

[81] P. Mecocci, M.C. Polidori, A. Cherubini, T. Ingegni, P. Mattioli, M. Catani, P. Rinaldi, R. Cecchetti, W. Stahl, U. Senin and M.F. Beal, Lymphocyte oxidative DNA damage and plasma antioxidants in Alzheimer disease, Arch Neurol 59 (2002), 794-798.

[82] P. Mecocci, M.C. Polidori, T. Ingegni, A. Cherubini, F. Chionne, R. Cecchetti and U. Senin, Oxidative damage to DNA in lymphocytes from AD patients, Neurology $\mathbf{5 1}$ (1998), 1014-1017.

[83] P. Mecocci, Oxidative stress in mild cognitive impairment and Alzheimer disease: a continuum, J Alzheimers Dis 6 (2004), 159-163.

[84] A. Metastasio, P. Rinaldi, R. Tarducci, E. Mariani, F.T. Feliziani, A. Cherubini, G.P. Pelliccioli, G. Gobbi, U. Senin and P. Mecocci, Conversion of MCI to dementia: Role of proton magnetic resonance spectroscopy, Neurobiol Aging 27 (2006), 926-932.

[85] L. Migliore, R. Colognato, F. Coppede, G. Tognoni, B. Nucciarone and G. Siciliano. Oxidative DNA damage in peripheral leukocytes of mild cognitive impairment and $\mathrm{AD}$ patients, Neurobiol Aging 26 (2005), 567-573.

[86] P.J. Modrego, N. Fayed and M.A. Pina, Conversion from mild cognitive impairment to probable Alzheimer's disease predicted by brain magnetic resonance spectroscopy, Am J Psychiatry 162 (2005), 667-675.

[87] P.J. Modrego and J. Ferrandez, Depression in patients with mild cognitive impairment increases the risk of developing dementia of Alzheimer type: a prospective cohort study, Arch Neurol 61 (2004), 1290-1293.

[88] P.J. Modrego, Predictors of conversion to dementia of probable Alzheimer type in patients with mild cognitive impairment, Curr Alzheimer Res 3 (2006), 161-170.

[89] R. Monastero, K. Palmer, C. Qiu, B. Winblad and L. Fratiglioni, Heterogeneity in risk factors for cognitive impairment, no dementia: population-based longitudinal study from the Kungsholmen Project, Am J Geriatr Psychiatry 15 (2007), 60-69.

[90] T.J. Montine, J.F. Quinn, D. Milatovic, L.C. Silbert, T. Dang, S. Sanchez, E. Terry, L.J. Roberts 2nd, J.A. Kaye and J.D. Morrow, Peripheral F2-isoprostanes and F4-neuroprostanes are not increased in Alzheimer's disease, Ann Neurol 52 (2002), 175-179.

[91] J.C. Morris, The Clinical Dementia Rating (CDR): current version and scoring rules, Neurology 43 (1993), 2412-2414.

[92] L. Mosconi, D. Perani, S. Sorbi, K. Herholz, B. Nacmias, V. Holthoff, E. Salmon, J.C. Baron, M.T. De Cristofaro, A. Padovani, B. Borroni, M. Franceschi, L. Bracco and A. Pupi, MCI conversion to dementia and the APOE genotype: a prediction study with FDG-PET, Neurology 63 (2004), 23322340.

[93] Z.S. Nasreddine, N.A. Phillips, V. Bedirian, S. Charbonneau, V. Whitehead, I. Collin, J.L Cummings and H. Chertkow, The Montreal Cognitive Assessment, MoCA: a brief screening tool for mild cognitive impairment, $J$ Am Geriatr Soc $\mathbf{5 3}$ (2005), 695-699.

[94] K. Palmer, H.X. Wang, L. Backman, B. Winblad and L. Fratiglioni, Differential evolution of cognitive impairment in nondemented older persons: results from the Kungsholmen Project, Am J Psychiatry 159 (2002), 436-442.

[95] F. Panza, A. D’Introno, A.M. Colacicco, C. Capurso, A. Del Parigi, R.J. Caselli, A. Pilotto, G. Argentieri, P.L. Scapicchio, E. Scafato, A. Capurso and V. Solfrizzi, Current epidemiology of mild cognitive impairment and other predementia syndromes, Am J Geriatr Psychiatry 13 (2005), 633-644.

[96] K. Peres, V. Chrysostome, C. Fabrigoule, J.M. Orgogozo, J.F. Dartigues and P. Barberger-Gateau, Restriction in com- 
plex activities of daily living in MCI: impact on outcome, Neurology 67 (2006), 461-466.

[97] R. Perneczky, C. Pohl, C. Sorg, J. Hartmann, N. Tosic, T. Grimmer, S. Heitele and A. Kurz, Impairment of activities of daily living requiring memory or complex reasoning as part of the MCI syndrome, Int J Geriatr Psychiatry 21 (2006), $158-162$.

[98] R.C. Petersen, R. Doody, A. Kurz, R.C. Mohs, J.C. Morris, P.V. Rabins, K. Ritchie, M. Rossor, L. Thal and B. Winblad, Current concepts in mild cognitive impairment, Arch Neurol 58 (2001), 1985-1992.

[99] R.C. Petersen, G.E. Smith, S.C. Waring, R.J. Ivnik, E.G. Tangalos and E. Kokmen, Mild cognitive impairment: clinical characterization and outcome, Arch Neurol 56 (1999), 303-308.

[100] R.C. Petersen, J.E. Parisi, D.W. Dickson, K.A. Johnson, D.S. Knopman, B.F. Boeve, G.A. Jicha, R.J. Ivnik, G.E. Smith, E.G. Tangalos, H. Braak and E. Kokmen, Neuropathologic features of amnestic mild cognitive impairment, Arch Neurol 63 (2006), 665-672.

[101] R.C. Petersen, G.E. Smith, R.J. Ivnik, E.G. Tangalos, D.J. Schaid, S.N. Thibodeau, E. Kokmen, S.C. Waring and L.T. Kurland, Apolipoprotein E status as a predictor of the development of Alzheimer's disease in memory-impaired individuals, JAMA 273 (1995), 1274-1278.

[102] R.C. Petersen, R.G. Thomas, M. Grundman, D. Bennett, R. Doody, S. Ferris, D. Galasko, S. Jin, J. Kaye, A. Levey, E. Pfeiffer, M. Sano, C.H. van Dyck and L.J. Thal, Alzheimer's Disease Cooperative Study Group, Vitamin E and donepezil for the treatment of mild cognitive impairment, $N$ Engl J Med 352 (2005), 2379-2388.

[103] R.C. Petersen, Mild Cognitive Impairment as a diagnostic entity, J Intern Med 256 (2004), 183-194.

[104] P.P. Pioggiosi, D. Berardi, B. Ferrari, R. Quartesan and D. De Ronchi, Occurrence of cognitive impairment after age 90: MCI and other broadly used concepts, Brain Res Bull $\mathbf{6 8}$ (2006), 227-232.

[105] L.J. Podewils, E. Guallar, L.H. Kuller, L.P. Fried, O.L. Lopez, M. Carlson and C.G. Lyketsos, Physical activity, APOE genotype, and dementia risk: findings from the Cardiovascular Health Cognition Study, Am J Epidemiol 161 (2005), 639-651.

[106] M.C. Polidori, E. Mariani, P. Mecocci and G. Nelles, Congestive heart failure and Alzheimer's disease, Neurol Res $\mathbf{2 8}$ (2006), 588-594.

[107] D. Praticò, C.M. Clark, F. Liun, J. Rokach, V.Y. Lee and J.Q. Trojanowski, Increase of brain oxidative stress in mild cognitive impairment: a possible predictor of Alzheimer disease, Arch Neurol 59 (2002), 972-976.

[108] D. Praticò, F(2)-isoprostanes: sensitive and specific noninvasive indices of lipid peroxidation in vivo, Atherosclerosis 147 (1999), 1-10.

[109] E.E. Reich, W.R. Markesbery, L.J. Roberts 2nd, L.L. Swift, J.D. Morrow and T.J. Montine, Brain regional quantification of F-ring and D-/E-ring isoprostanes and neuroprostanes in Alzheimer's disease, Am J Pathol 158 (2001), 293-297.

[110] P. Rinaldi, M.C. Polidori, A. Metastasio, E. Mariani, P. Mattioli, A. Cherubini, M. Catani, R. Cecchetti, U. Senin and P. Mecocci, Plasma antioxidants are similarly depleted in mild cognitive impairment and in Alzheimer's disease, Neurobiol Aging 24 (2003), 915-919.

[111] K. Ritchie, S. Artero and J. Touchon, Classification criteria for mild cognitive impairment: a population-based validation study, Neurology 56 (2001), 37-42.
[112] K. Ritchie, B. Ledesert and J. Touchon, Suclinical cognitive impairment: epidemiology and clinical characteristics, Compr Psychiatr 41 (2000), 61-65.

[113] P.H. Robert, C. Berr, M. Volteau, C. Bertogliati, M. Benoit, M. Sarazin, S. Legrain and B. Dubois, the PreAL study, Apathy in patients with mild cognitive impairment and the risk of developing dementia of Alzheimer's disease: a oneyear follow-up study, Clin Neurol Neurosurg 108 (2006), 733-736.

[114] P.B. Rosenberg, D. Johnston and C.G. Lyketsos, A clinical approach to mild cognitive impairment, Am J Psychiatry 163 (2006), 1884-1890.

[115] H. Rusinek, S. De Santi, D. Frid, W.H. Tsui, C.Y. Tarshish, A. Convit and de M.J. Leon, Regional brain atrophy rate predicts future cognitive decline: 6-year longitudinal MR imaging study of normal aging, Radiology 229 (2003), 691-696.

[116] J.M. Schott, J. Kennedy and N.C. Fox, New developments in mild cognitive impairment and Alzheimer's disease, Curr Opin Neurol 19 (2006), 552-558.

[117] F. Shalit, B. Sredni, C. Brodie, E. Kott and M. Huberman, Tlymphocyte subpopulations and activation markers correlate with severity of Alzheimer's disease, Clin Immunol Immunopathol 75 (1995), 246-250.

[118] W.R. Shankle, A.K. Romney, J. Hara, D. Fortier, M.B. Dick, J.M. Chen, T. Chan and X. Sun, Methods to improve the detection of mild cognitive impairment, Proc Natl Acad Sci USA 102 (2005), 4919-4924.

[119] G.W. Small, V. Kepe, L.M. Ercoli, P. Siddarth, S.Y. Bookheimer, K.J. Miller, H. Lavretsky, A.C. Burggren, G.M. Cole, H.V. Vinters, P.M Thompson, S.C. Huang, N. Satyamurthy, M.E. Phelps and J.R. Barrio, PET of brain amyloid and tau in mild cognitive impairment, $N$ Engl J Med 355 (2006), 2652-2663.

[120] V. Solfrizzi, F. Panza, A.M. Colacicco, A. D'Introno, C. Capurso, F. Torres, F. Grigoletto, S. Maggi, A. Del Parigi, E.M. Reiman, R.J. Caselli, E. Scafato, G. Farchi and A. Capurso, Italian Longitudinal Study on Aging Working Group, Vascular risk factors, incidence of MCI, and rates of progression to dementia, Neurology 63 (2004), 1882-1891.

[121] T.R. Stoub, L. deToledo-Morrell, G.T. Stebbins, S. Leurgans, D.A. Bennett and R.C. Shah, Hippocampal disconnection contributes to memory dysfunction in individuals at risk for Alzheimer's disease, Proc Natl Acad Sci USA 103 (2006), 10041-10045.

[122] M.H. Tabert, J.J. Manly, X. Liu, G.H. Pelton, S. Rosenblum, M. Jacobs, D. Zamora, M. Goodkind, K. Bell, Y. Stern and D.P. Devanand, Neuropsychological prediction of conversion to Alzheimer disease in patients with mild cognitive impairment, Arch Gen Psychiatry 63 (2006), 916-924.

[123] S. Tervo, M. Kivipelto, T. Hanninen, M. Vanhanen, M. Hallikainen, A. Mannermaa and H. Soininen, Incidence and risk factors for mild cognitive impairment: a population-based three-year follow-up study of cognitively healthy elderly subjects, Dement Geriatr Cogn Disord 17 (2004), 196-203.

[124] J.G. van Uffelen, M. Hopman-Rock, A. Chin, M.J. Paw and W. van Mechelen, Protocol for Project FACT: a randomised controlled trial on the effect of a walking program and vitamin B supplementation on the rate of cognitive decline and psychosocial wellbeing in older adults with mild cognitive impairment [ISRCTN19227688], BMC Geriatr 23 (2005), 18.

[125] J. Verghese, A. LeValley, C. Derby, G. Kuslansky, M. Katz, C. Hall, H. Buschke and R.B. Lipton, Leisure activities and 
the risk of amnestic mild cognitive impairment in the elderly, Neurology 66 (2006), 821-827.

[126] P.J. Visser, F.R. Verhey, P.A. Hofman, P. Scheltens and J. Jolles, Medial temporal lobe atrophy predicts Alzheimer's disease in patients with minor cognitive impairment, J Neurol Neurosurg Psychiatry 72 (2002), 491-497.

[127] J. Wang, W.R. Markesbery and M.A. Lovell, Increased oxidative damage in nuclear and mitochondrial DNA in mild cognitive impairment, J Neurochem 96 (2006), 825-832.

[128] WHO, The ICD-10 classification of mental and behavioural disorders: diagnostic criteria for research, WHO, Geneva (1993).

[129] B. Winblad, K. Palmer, M. Kivipelto, V. Jelic, L. Fratiglioni, L.O. Wahlund, A. Nordberg, L. Backman, M. Albert, O. Almkvist, H. Arai, H. Basun, K. Blennow, M. de Leon, C.
DeCarli, T. Erkinjuntti, E. Giacobini, C. Graff, J. Hardy, C. Jack, A. Jorm, K. Ritchie, C. van Duijn, P. Visser and R.C. Petersen, Mild cognitive impairment-beyond controversies, towards a consensus: report of the International Working Group on Mild Cognitive Impairment, J Intern Med 256 (2004), 240-246.

[130] B. Winblad, A. Wimo, K. Engedal, H. Soininen, F. Verhey, G. Waldemar, A.L. Wetterholm, A. Haglund, R. Zhang and R. Schindler, 3-year study of donepezil therapy in Alzheimer's disease: effects of early and continuous therapy, Dement Geriatr Cogn Disord 21 (2006), 353-363.

[131] K. Yaffe, T. Blackwell, R. Gore, L. Sands, V. Reus and W.S. Browner, Depressive symptoms and cognitive decline in nondemented elderly women: a prospective study, Arch Gen Psychiatry 56 (1999), 425-430. 